\title{
IDENTIFICATION OF THE CAUSES OF INCREASED VIBRATIONS IN THE HIGH-POWER MULTI-STAGE ROTODYNAMIC PUMP
}

\author{
Grzegorz ŻYWICA ${ }^{1}$, Pawel FLASZYŃSKI ${ }^{2}$, \\ Tomasz Z. KACZMARCZYK ${ }^{3}$, Hubert KOPEĆ ${ }^{4}$ \\ ${ }^{1,2,3}$ Institute of Fluid Flow Machinery, Polish Academy of Sciences \\ ${ }^{1}$ gzywica@imp.gda.pl, ${ }^{2}$ pflaszyn@imp.gda.pl, ${ }^{3}$ tkaczmarczyk@imp.gda.pl \\ ${ }^{4}$ Group Powen-Wafapomp SA, ${ }^{4}$ hubert.kopec@ powen.com.pl
}

\begin{abstract}
The article discusses the vibrodiagnostic tests of a multi-stage high-power rotodynamic pump. The tested pump was operated as a feed water pump in an industrial combined heat and power plant. However, some time ago, its dynamic performance started to deteriorate. Therefore, diagnostic tests were carried out, the aim of which was to identify the reasons for the increased vibration level and to minimise it. The scope of the performed work included both the analysis of possible excitation forces originating from the flow system and measurements of the pump vibrations at different power levels. Additionally, at selected measuring points, vibration velocity spectra were registered and eigenfrequencies were determined. The analysis of the obtained results allowed to clearly identify the causes of dynamic problems and introduce changes that enable their elimination.
\end{abstract}

Keywords: vibrodiagnotics, pump vibrations, rotodynamic pump, high-power pump

\section{IDENTYFIKACJA PRZYCZYN PODWYŻSZONEGO POZIOMU DRGAŃ WIELOSTOPNIOWEJ POMPY WIROWEJ DUŻEJ MOCY}

\section{Streszczenie}

W artykule omówione zostały badania wibrodiagnostyczne wielostopniowej pompy wirowej o mocy 3 MW. Badana pompa pracowała jako pompa wody zasilającej w elektrociepłowni przemysłowej, ale od pewnego czasu jej stan dynamiczny pogarszał się. Dlatego przeprowadzone zostały badania diagnostyczne, których celem była identyfikacja przyczyn podwyższonego poziomu drgań oraz ich minimalizacja. Zakres wykonanych prac obejmował zarówno analizę możliwych wymuszeń pochodzących z układu przepływowego jak i pomiary wielkości charakterystycznych drgań pompy przy różnych poziomach mocy. Dodatkowo, w wybranych punktach pomiarowych, zarejestrowano również rozkłady częstotliwościowe drgań i wyznaczono częstotliwości drgań własnych. Analiza uzyskanych wyników pozwoliła na jednoznaczną identyfikację przyczyn problemów dynamicznych oraz wprowadzenie zmian umożliwiających ich eliminację.

Słowa kluczowe: wibrodiagnostyka, drgania pompy, pompa wirowa, pompa dużej mocy

\section{INTRODUCTION}

Vibrodiagnostic methods are extensively employed to estimate the technical condition of machinery and to identify or predict their malfunctioning. The advantages of diagnostic methods based on vibration analysis make for a large range of applications, including various types of fluid-flow machines - in particular, high-power machines, where fitting them with diagnostic systems have become a standard on the market.

Vibrodiagnostics is also used in assessing the technical condition and proper functioning of different types of pumps. Rotodynamic pumps are no exception in this matter and in order to inspect their operation, it is possible to apply standard diagnostic methods dedicated to rotating machinery [10]. In testing hydraulic machines the vibration level is usually the basic measured parameter. Supplementary measurements are done to measure, among other things, the pressure pulsation [1], noise level [6], temperature distributions on the surface of objects (thermovision) or their geometry using laser tools. Such measurements allow detecting symptoms of various defects that could have been caused by flow [13], mechanical [1] or electrical [8] phenomena. Defects occurring in working parts or driving elements of some machines often lead to higher energy consumption, which can be also used as a sign of failure [12]. It is known to use nondestructive testing methods (such as, for example, ultrasound scanning, magnetic method, gamma-radiography or capillary examination [11]) in order to detect damage to individual pump components.

Rotodynamic pumps can be used in many industries [5, 15], due to their ability to work with so many different working mediums, throughout a wide operating range in terms of pressure and flow rate. Furthermore, they are perceived as highly 
reliable devices [3]. Depending on the size of the pump and the role it plays in the installation, different levels of monitoring its technical condition are used. In the case of low-power pumps, repairs are usually done only after a failure occurred. The operation of medium power pumps is usually controlled at certain time intervals, and the replacement of worn parts is carried out if any damage is found or during periodic maintenance checks. High-power pumps are often monitored $24 / 7$ and sometimes they are coupled with systems that allow predicting their technical condition depending on specific operating conditions [7]. This helps in increasing the operational reliability as well as in planning the repair work and at the same time reduces running-costs [4]. This is of particular importance for pumps considered to be critical, such as the ones that are operated in conventional [14] or nuclear power stations [9]. In that regard, it is noteworthy that testing methods based on neural networks and artificial intelligence have gained in popularity [2,9].

This article presents the results of research on a multi-stage high-power (3.3 MW) rotodynamic pump. During standard maintenance checks, a deterioration in the dynamic performance of the pump was noticed, which made its further operation impossible at a certain range of loads. Therefore, extended diagnostic tests were carried out at various operational loads, and the obtained results were thoroughly analysed. Only after the results of several various measurements were appropriately processed and compared to each other, the reason for the decrease in the operational reliability of the pump was discovered. Furthermore, finding the cause of the increased vibration level could not have been possible without an in-depth analysis of the turbine's construction.

\section{OBJECT OF INVESTIGATION}

The test object was the multi-stage rotodynamic pump that operated as a feed pump in the working cycle of an industrial combined heat and power plant. The pumped hot water feeds a steam boiler of one of the power units. The pump has several stages and each of them is comprised of a stage ring, rotor and stator. The external tightness is provided by glands screwed both to the suction casing and the discharge casing. The slide bearings' supports are located at the ends of the shaft and are screwed to the glands' covers. The pump's shaft is supported by two radial bearings and one bidirectional thrust bearing. The pump rests on the base plate using four footers connected to the casing. The suction and discharge ports are positioned vertically upwards. The pump is driven by an electric motor, via a gearbox coupled with a hydrodynamic coupling. A diagram of the pumping engine is presented in Fig. 1, and its basic parameters are listed in Table 1.


Fig. 1. Diagram of the pump and motor unit ( 1 - electric motor, 2 - gear, 3 - pump)

Table 1. Basic specification of the pumping engine

\begin{tabular}{|c|c|}
\hline \multicolumn{2}{|c|}{ Feed pump } \\
\hline Country of origin & Poland \\
\hline Type of pump & rotodynamic, multi-stage \\
\hline Working medium & water (clean and hot) \\
\hline Mass & $3,435 \mathrm{~kg}$ \\
\hline Power of the drive motor & $3,300 \mathrm{~kW}$ \\
\hline Maximum flow rate & $490 \mathrm{~m}^{3} / \mathrm{h}$ \\
\hline Minimum flow rate & $90 \mathrm{~m}^{3} / \mathrm{h}$ \\
\hline Delivery head & $1,900 \mathrm{~m}$ \\
\hline Maximum pressure & $240 \mathrm{bar}$ \\
\hline Rated speed & $4,570 \mathrm{rpm}$ \\
\hline
\end{tabular}

The tested pump is capable of operating throughout a wide range of volumetric flow rates $\left(90 \mathrm{~m}^{3} / \mathrm{h}-490 \mathrm{~m}^{3} / \mathrm{h}\right)$. The recommended operating range is from 0.7 to 1.2 of the nominal flow. Changing the pump's operation can be obtained in two ways: by altering the rotational speed of the motor or by regulating the valve in the discharge port (throttling).

\section{DIAGNOSTIC TESTS}

Within a framework of the pump investigation, extended diagnostic tests were carried out in order to get as much information as possible about the dynamic performance. Some tests were done during normal operation (at different operational loads) and the other only after the machine was stopped. The following research was scheduled and conducted: assessment of the dynamic state, analysis of the vibration spectra and determination of eigenfrequencies. The results of the research are discussed in several subsequent sections of the article. In addition, as part of the supplementary measurements, temperature distributions on the surface of the pump were checked using a thermal imaging camera. The results of these measurements did not show that temperature exceeded the acceptable range, and therefore they will not be discussed further. 
All measurements described in the following part of the article were performed at the measurement locations shown in Fig. 2. Measurement nodes, at which the dynamic state assessment was performed, are marked with rectangles (nodes No. 2 and 5). Measurements were made in directions aligned with the coordinate system, whereby measurements in the axial direction $(Z)$ were only made on an ad hoc basis.

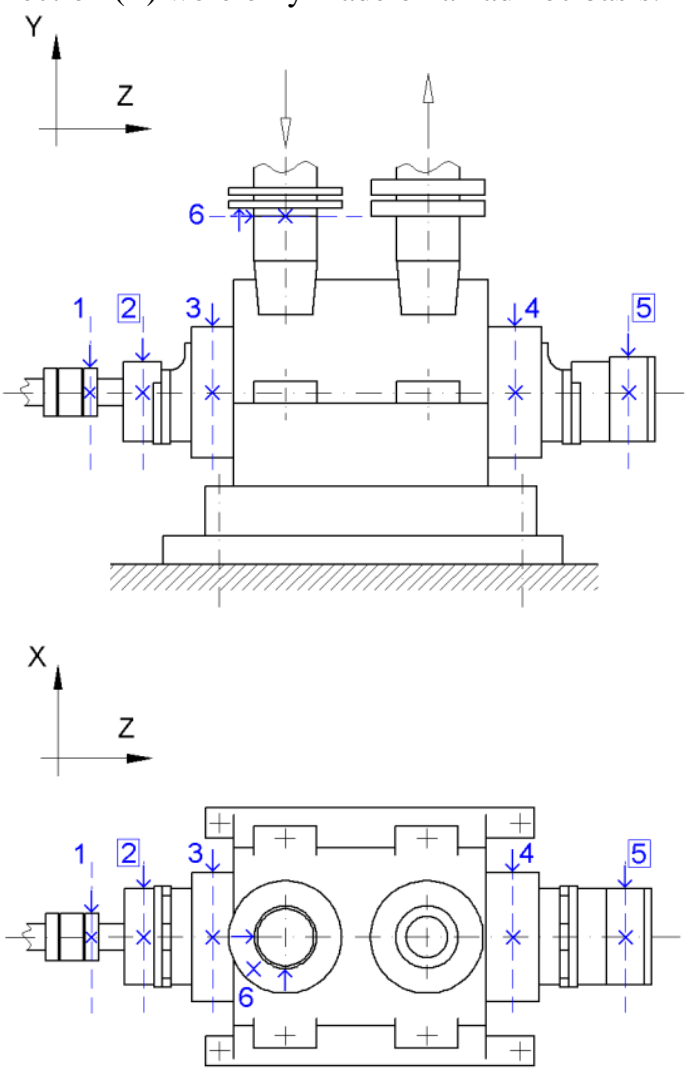

Fig. 2. Arrangement of the measuring points on the tested pump ( 1 - driven shaft end, 2 bearing housing, 3 and 4 - pump housing on the suction and discharge side, 5 - thrust bearing housing, 6 - suction port)

Two portable vibration analyzers were used, namely Emerson CSI 2140 Machinery Health Analyzer with a four-channel data collection module and DIAMOND 401A (a two-channel device manufactured by MBJ Electronics). Uniaxial accelerometers (attached using magnetic bases) were employed as sensors.

\subsection{Dynamic state assessment}

Vibration level measurements on the nonrotating parts of the pump were carried out in accordance with the ISO 10816-1 and ISO 10816-7 standards. The first of those standards establishes general guidelines for the measurement and evaluation of vibration of machinery. The second standard gives instructions for the evaluation of vibration on rotodynamic pumps for industrial applications. Based on the ISO 10816-7 standard, the pump has been classified in category I, i.e. pumps whose operation requires a high level of reliability, availability and safety. Due to the power rating the pump should be assigned to the group of devices with power above $200 \mathrm{~kW}$. According to the above-mentioned category and group, the acceptable vibration levels are presented in Table 2. The Vrms and Ap-p parameters denote, respectively, the root-mean-square (rms) vibration velocity and peak-to-peak vibration amplitude.

Table 2. Allowable vibration levels of the tested pump (according to the ISO 10816-7 standard)

\begin{tabular}{|c|c|c|}
\hline Zone & Vrms [mm/s] & Ap-p [ $\mathbf{\mu m}]$ \\
\hline A & 3.5 & 50 \\
\hline B & 5.0 & 80 \\
\hline C & 7.6 & 130 \\
\hline D & $>7.6$ & $>130$ \\
\hline
\end{tabular}

The Vrms parameter is the basic parameter taken into account during the assessment of the dynamic state of high-speed pumps. The measurement of the peak-to-peak vibration amplitude is recommended as an additional evaluation criterion only for low-speed pumps. In the case described herein, the measurement of the peak-to-peak vibration amplitude was made as a complementary one, in order to obtain additional information about the test object. As the pump in question has been operating for several years, the expected vibration level should be assigned to Zone B. This would mean the possibility of long-term operation without any restrictions.

The evaluation of the dynamic state of the pump was carried out for four operating modes, corresponding to the following mass flow rates: 240, 260, 280 and $300 \mathrm{t} / \mathrm{h}$. Those flow rate values were chosen due to the fact that problems with the dynamic performance existed only in the range of flow rates in which all of them are contained. The obtained results are given in Table 3 .

Table 3. Results of vibration measurements of the pump obtained at different load levels

\begin{tabular}{|c|c|c|c|c|}
\hline \multirow{2}{*}{ Q [t/h] } & \multicolumn{4}{|c|}{ Vrms [mm/s] } \\
\cline { 2 - 5 } & \multicolumn{2}{|c|}{$\mathbf{2}$} & $\mathbf{5}$ & $\mathbf{Y}$ \\
\cline { 2 - 5 } & $\mathbf{X}$ & $\mathbf{Y}$ & $\mathbf{X}$ & $\mathbf{5}$ \\
\hline 240 & 9.20 & 7.12 & 2.76 & 2.75 \\
\hline 260 & 8.82 & 6.79 & 2.57 & 2.49 \\
\hline 280 & 8.28 & 7.94 & 2.45 & 2.22 \\
\hline 300 & 8.62 & 6.34 & 2.40 & 2.19 \\
\hline
\end{tabular}

According to the measurement results, it is clear that the tested machine should be assigned to Zone $\mathrm{D}$, which means that it should be stopped immediately. In the worst case, the rms vibration velocity reached a value of $9.2 \mathrm{~mm} / \mathrm{s}$. As stated by the ISO 10816-7 standard, further running at such a high level of vibration could have caused damage.

In this respect, it should be noted, that the permissible level of vibration $(\mathrm{Vrms}=5 \mathrm{~mm} / \mathrm{s}$ ) was exceeded in two directions perpendicular to the rotor axis ( $2 \mathrm{X}$ and $2 \mathrm{Y}$ ), and only at one bearing support. Both the level of vibration measured at the 
second bearing casing as well as at all other measuring points (see Fig. 2) was within permissible limits for new machines (i.e. was below $3.5 \mathrm{~mm} / \mathrm{s}$ ). When looking at the results of the measurement of peak-to-peak vibration amplitudes, where the admissible values were exceeded only in one measuring node, similar conclusions could have been drawn. It could have been concluded that the machine should no longer be used (Zone D), despite the fact that dynamic problems only occurred within one bearing support. Finally, it was concluded that further research was needed.

\subsection{Vibration frequency analysis}

The assessment of the dynamic state of the pump showed that dynamic problems occurred only locally - within one bearing support, on the suction side. Therefore, it was decided to conduct vibration spectra analysis for the measured vibrations, focusing on one bearing support. The analysis of vibration in the frequency domain allows determining at which frequencies the main vibration components occur. It is possible to obtain much more information than when analyzing only the values of the Vrms and Ap-p parameters. It is possible to get much more information than when analysing only the values of the Vrms and Ap-p parameters. This type of analysis, in combination with a basic knowledge about the construction of the analysed object, enables an experienced diagnostician to indicate sources of vibration as well as facilitates localising a design error or construction defect.

Basic characteristic frequencies of the tested pump are depicted in Table 4. They were determined on the basis of technical documentation. Since the rotational speed of the pump impeller varied during measurements, no constant rotational frequency could be determined. Therefore, in this case, the vibration components of the impeller were linked to the current rotational speed. In regard to this fact, Table 4 lists the frequency ranges corresponding to the range of rotational speeds of the impeller that were registered during the research. Vibration originating from the blading result from the number of blades in individual stages of the pump. There were 8 blades in the first stage of the pump, and 7 blades in the others.

Table 4. Characteristic frequencies of the pump

\begin{tabular}{|c|c|}
\hline Defect & Frequency (Hz) \\
\hline \multicolumn{2}{|c|}{ Pump rotor } \\
\hline Unbalance & $70-72$ \\
\hline Misalignment/bending & $70-72 ; 140-142 ; 210-216$ \\
\hline $\begin{array}{c}\text { Excessive bearing } \\
\text { clearance or instability }\end{array}$ & $23.3-24 ; 35-36$ \\
\hline Electrical excitation & $50 ; 100$ \\
\hline \multicolumn{2}{|c|}{ Fluid-flow system } \\
\hline $\begin{array}{c}\text { Vibrations from the 1-st } \\
\text { stage of the pump }\end{array}$ & $560-576$ \\
\hline $\begin{array}{c}\text { Vibrations from 2-5 } \\
\text { stages of the pump }\end{array}$ & $490-504$ \\
\hline
\end{tabular}

All vibration velocity spectra were analysed in the range of $0-1600 \mathrm{~Hz}$, with a resolution of $1 \mathrm{~Hz}$. The upper limit of the frequency range was assumed based on the recommendations found in the ISO 10816 standard, as greater than 2.5 times the impeller blade frequency. It was possible to register high-frequency vibration, related to the operation of the blading. The obtained vibration velocity spectra of the bearing support (that proved to be problematic), located at the suction side, were presented in Figs. 3 and 4.

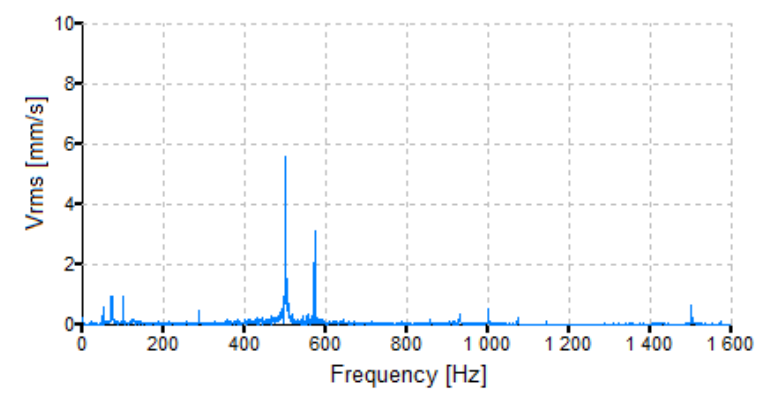

Fig. 3. Frequency spectrum of the vibration velocity registered at the bearing support in the $\mathrm{X}$ direction when the pump operated with a flow rate of $240 \mathrm{t} / \mathrm{h}$

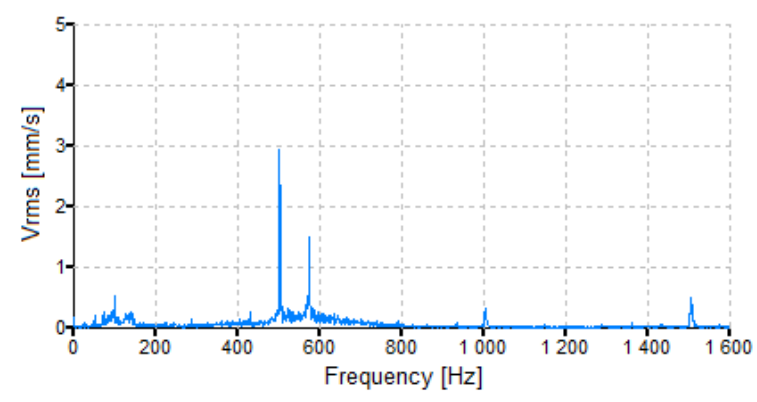

Fig. 4. Frequency spectrum of the vibration velocity registered at the bearing support in the Y direction when the pump operated with a flow rate of $240 \mathrm{t} / \mathrm{h}$

Similar graphs were prepared for other flow rates of the pump. The highest level of vibration, taking into account two directions, occurred at frequencies from the range of $490-500 \mathrm{~Hz}$. The rms vibration velocities at these frequencies were different for different flow rates, and some of them exceeded $5 \mathrm{~mm} / \mathrm{s}$. On the analysed spectra, the second highest vibration component occurred in the frequency range $560-573 \mathrm{~Hz}$. It was about $50 \%$ lower than the highest vibration component on all analysed graphs. Other vibration components were much smaller, and thus had a much smaller impact on the dynamic state of the machine.

Having looked at the characteristic frequencies listed in Table 4, it can be stated that the vibrations originating from the pump's fluid-flow system had the most significant impact on the vibration level of the bearing support. The highest vibration components occurred at frequencies corresponding 
to the blade frequencies of subsequent stages of the pump. At other measuring points, vibration components could have been observed at the same frequencies but all of them were significantly smaller.

After analysing all results of the vibration frequency analysis of the pump it became clear that the vibrations originating from the fluid-flow system were so intense that they were observed at all measuring points. However, only at one measuring node that was located on the bearing support (suction side), the permissible vibration level was exceeded. To find out the reason for this situation, it was decided to perform a modal analysis to determine the frequencies of vibrations of the pump subassemblies.

\subsection{Eigenfrequencies}

The modal analysis was performed to check whether the characteristic frequencies of the system (which were a response to a dynamic excitation) do not coincide with its eigenfrequencies. Due to prevailing conditions at the measurement site, only simplified modal tests were carried out, the purpose of which was to identify only natural frequencies (without identifying damping coefficients and natural vibration modes). The tests were carried out in a frequency range of $0-1600 \mathrm{~Hz}$ (with a resolution of $1 \mathrm{~Hz}$ ). Excitations were applied using a set of hammers of various weights, with properly selected intermediate elements. Thanks to this, it was possible to adjust the excitation characteristics to individual measuring points (Fig. 2).

Considering the limited number of pages of the article, only selected research results related to the bearing support located at the suction side are presented. Based on the dynamic response registered at the remaining measuring points, it can be concluded that not a single eigenfrequency was consistent with the excitation frequencies originating from the fluid-flow system. This was also the case for the rotor's eigenfrequencies that happened to occur at $194 \mathrm{~Hz}$ and $202 \mathrm{~Hz}$, depending on the excitation direction. At higher frequencies, no maxima were noticed on the registered graphs presenting vibration velocity spectra of the rotor.

The modal characteristics of the bearing support at the suction side proved to be crucial for explaining the increased vibration level. It is depicted in Figs. 5 and 6. Based on the recorded dynamic response, it can be concluded that the bearing support has several natural vibration modes in a wide frequency range. Having regard to the characteristic frequencies of the tested machine, natural vibration modes that occurred in the frequency range $500-600 \mathrm{~Hz}$ are of most importance. It turned out that global maxima of vibration were present in this range, resulting in the occurrence of eigenfrequencies.

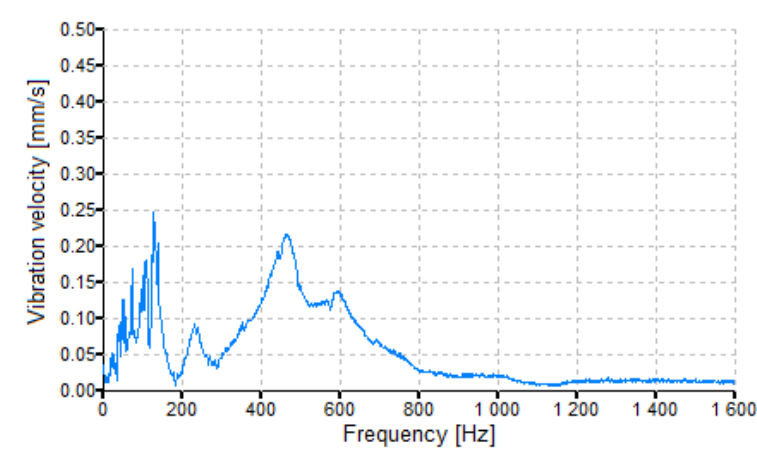

Fig. 5. The bearing support's dynamic response to an impulse excitation that was applied in the $\mathrm{X}$ direction



Fig. 6. The bearing support's dynamic response to an impulse excitation that was applied in the $\mathrm{Y}$ direction

The most important eigenfrequencies of the bearing support in the horizontal direction appeared at the following frequencies: $72 \mathrm{~Hz}, 107 \mathrm{~Hz}, 127$ $\mathrm{Hz}, 465 \mathrm{~Hz}$ and $595 \mathrm{~Hz}$. The last two frequencies were close to the frequencies of the excitations arising in the fluid-flow system of the pump, similar to how it was with the bearing support's dynamic response in the vertical direction (Y). As can be seen in Fig. 6, the highest vibration level in the $\mathrm{Y}$ direction was observed at the following frequencies: $50 \mathrm{~Hz}, 102,144 \mathrm{~Hz}, 476 \mathrm{~Hz}$ and 610 $\mathrm{Hz}$. As before, the two highest frequencies were close to the frequencies of the excitations arising in the fluid-flow system.

The detected eigenfrequencies are the causes of the high vibration level of the bearing support (at the suction side) during the pump's operation. The natural frequencies of this bearing coincided almost exactly with the excitation frequency. A direct comparison of the most important results is presented in Figs. 7 and 8. It can be unambiguously stated that the bearing support is somewhat problematic as it has natural vibration modes that occur at frequencies that are close to the frequencies of forces able to excite vibrations of the entire pump, which originate from its fluid-flow system. 


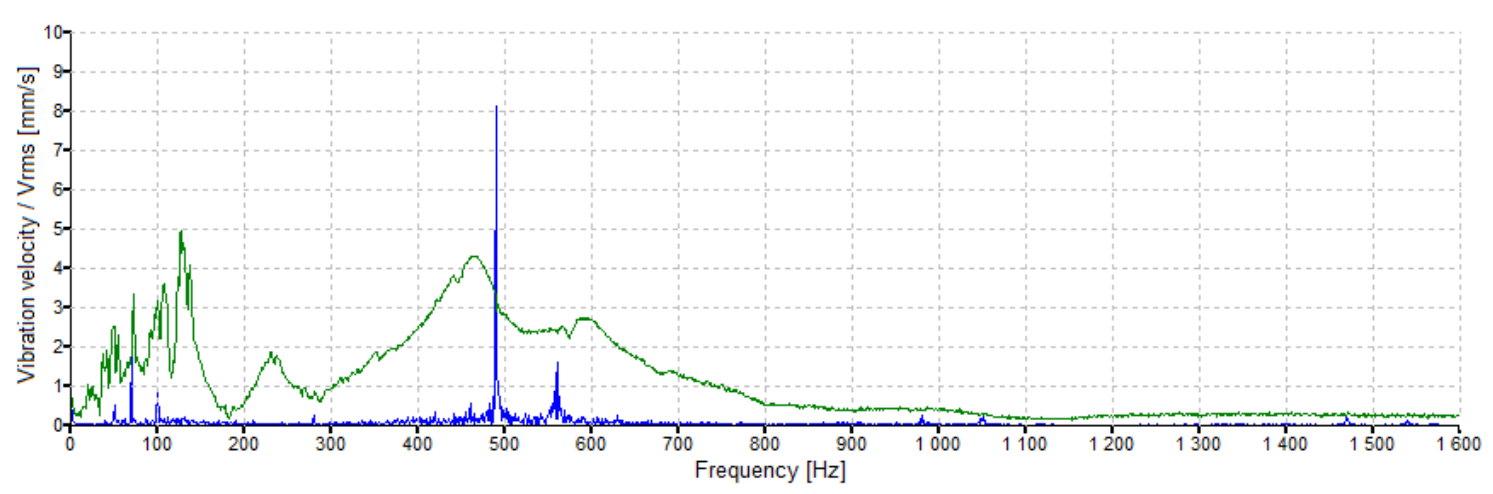

Fig. 7. Graph showing the vibration velocity spectrum of the rotor; a normal operation of the pump (blue line) is compared with the bearing support's dynamic response to an impulse excitation that was applied in the $\mathrm{X}$ direction (green line)

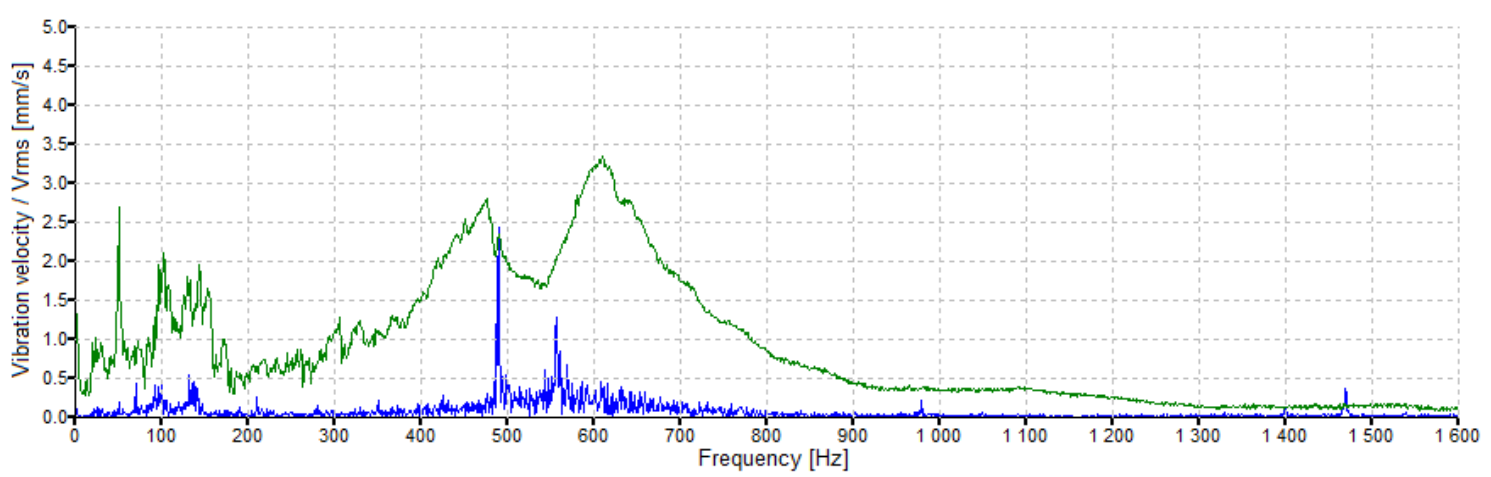

Fig. 8. Graph showing the vibration velocity spectrum of the rotor; a normal operation of the pump (blue line) is compared with the bearing support's dynamic response to an impulse excitation that was applied in the Y direction (green line)

During the pump tests, resonant vibrations could have been excited very easily. Even if the frequencies of excitation forces did not exactly match the eigenfrequencies an elevated vibration level was still observed. Therefore, when designing a fluid-flow machine, it is assumed that the frequencies of excitation forces should differ from eigenfrequencies of this machine by at least $15 \%$. This condition was not met in the case discussed.

At none of the remaining measuring points was the above-mentioned problem observed (which means that eigenfrequencies of the system were not so similar to the characteristic frequencies of the pump or the excitation frequencies). The proof for this lies in the low vibration level recorded during the operation of the pump in the remaining measuring points.

\section{MACHINE MODIFICATIONS AND CONTROL TESTS}

Since the reason for dynamic problems of the tested machine was coinciding the eigenfrequencies of the bearing support with the excitation frequency originating from the fluid-flow system, the easiest way to prevent excessive vibrations was to introduce some constructional changes in the mentioned support. It was recognised that such changes are not only the most effective, but also the cheapest method to improve the dynamic state. Another method of decreasing the level of pump vibrations would be to reduce the excitation coming from the fluid-flow system. Due to high costs of potential modernisation of the pump stages (which would involve the necessity of dismantling the machine and finishing or making new rotor discs) as well as the uncertain result of such actions, this method was abandoned.

The modal characteristics of the mechanical system can be changed by altering one of the following parameters: stiffness, damping or mass. In the case discussed here, it would be most beneficial to lower the eigenfrequencies that occurred at $465 \mathrm{~Hz}$ in the horizontal direction and at $489 \mathrm{~Hz}$ in the vertical direction, at the same time increasing the eigenfrequencies that appeared at $595 \mathrm{~Hz}$ and $588 \mathrm{~Hz}$ (respectively in the horizontal and vertical direction). Such changes could be obtained by an appropriate combination of the above-mentioned parameters - that is stiffness, damping and mass of the bearing support. It would be necessary to develop an accurate numerical model that would also have to be verified experimentally. Because the tested pump required a rapid intervention (the high vibration level prevented its further operation), it was decided to 
change only the mass of the bearing support as an ad hoc solution. This was done by loading the bearing housing with a properly selected weight. The eigenfrequencies that had occurred at approx. $480 \mathrm{~Hz}$ decreased by about $100 \mathrm{~Hz}$. After the modification, the rms vibration velocity of the bearing support was measured and compared with the results obtained before the modification (see Table 3).

Table 5. Results of vibration measurements of the bearing support registered at the suction side of the pump before and after the modification

\begin{tabular}{|c|c|c|c|c|}
\hline \multirow{3}{*}{ Q [t/h] } & \multicolumn{4}{|c|}{ Vrms [mm/s] } \\
\cline { 2 - 5 } & \multicolumn{3}{|c|}{$\mathbf{2}$} & \multicolumn{2}{|c|}{$\mathbf{2}$} \\
\cline { 2 - 5 } & $\mathbf{X}$ & $\mathbf{Y}$ & $\mathbf{X}$ & $\mathbf{Y}$ \\
\hline 240 & 9.2 & 7.1 & 3.4 & 3.1 \\
\hline 260 & 8.8 & 6.8 & 3.0 & 3.2 \\
\hline 280 & 8.3 & 7.9 & 3.0 & 3.2 \\
\hline 300 & 8.6 & 6.3 & 3.0 & 3.4 \\
\hline
\end{tabular}

The measurement results listed in Table 5 show that the taken ad hoc countermeasure has brought the desired effect. The vibration level of the bearing support decreased significantly for a whole range of mass flow rates, having now a level typical for newly commissioned machines. Owing to such a high reduction in the vibration level, the tested pump is fully operational and is being operated with no limitations.

\section{CONCLUSIONS}

After conducting diagnostic tests of the rotodynamic pump with an electric power of about 3 MW and analysing of the obtained results, one can draw the following conclusions:

- Results of the measured vibration parameters (Vrms and Ap-p) showed that the pump should be put out of service due to its dynamic state. High vibrations used to occur only on the bearing housing at the suction side. Vibration measurements carried out at all other measuring points did not reveal any dynamic problems. What is more, despite the fact that the pump has been operated for several years, the measured values of the Vrms parameter were similar to the values recommended for new machines (Zone A).

- The fluid-flow system of the pump has proved to be a source of the dynamic excitation. The eigenfrequencies of the pump pretty much coincided with the characteristic frequencies (determined as the product of the rotational speed of the impeller and the number of blades of individual stages). They were in a range of 490-504 $\mathrm{Hz}$ for an excitation taking place at the pump stages from 2 to 5 and in a range of $560-576 \mathrm{~Hz}$ for an excitation taking place at the first stage of the pump. As excitations of this type can be transmitted both by elastic vibrations of the working fluid and structural vibrations of the impeller and the casing, the components of these vibrations were observed virtually at all measuring points.

- Results of the conducted modal analysis showed that the eigenfrequencies of the bearing support (that was somewhat problematic in terms of its dynamic behaviour) are very close to the frequencies of excitations originating from the fluid-flow system. This means that vibration of this machine component can be easily excited during pump operation.

- Having taken into account all obtained research results, some constructional changes were introduced in order to reduce the maximum vibration level. The modification of the bearing support significantly decreased the eigenfrequencies as well as the overall vibration level of the pump. The control measurements showed that the vibrations of the modified pump decreased to a level that is typical for new machines, and what is the most important, the pump is fully operational.

\section{REFERENCES}

1. Adamkowski A, Żywica G, Janicki W, Lewandowski M. Propagation of structural vibrations and pressure waves in the hydropower turbines. In: Timofiejczuk et al. (eds.), Advances in Technical Diagnostics. ICDT 2016. Applied Condition Monitoring. $2018 ; 10: 29-46$. http://dx.doi.org/10.1007/978-3-319-62042-8_3

2. Barszcz T, Bielecki A, Romaniuk T. Application of probabilistic neural networks for detection of mechanical faults in electric motors. Electrical Review 2009; 8/2009: 37-41.

3. Budzilo B, Polok-Kowalska A. Two parametric assessment of water supply subsystem reliability operation for the town of Limanowa. Technical Transactions 2007; 2-S/2007: 29-38.

4. Hupa B, Nieśpiałowski K. Predykcyjny system monitoringu i diagnostyki pomp wirowych średniociśnieniowych. Napędy i Sterowanie 2011; 11/2011: 118-120.

5. Kaczmarczyk TZ, Żywica G, Ihnatowicz E. Experimental investigation on a rotodynamic pump operating in the cogeneration system with a low boiling working medium. Transactions of the Institute of Fluid-Flow Machinery 2016; 134: 63-87.

6. Kaczmarczyk TZ, Żywica G, Ihnatowicz E. Vibroacoustic diagnostics of a radial microturbine and a scroll expander operating in the organic Rankine cycle installation. Journal of Vibroengineering. 2016; 18(6): 4130-4147. http://dx.doi.org/10.21595/jve.2016.17167

7. Kim HE, Hwang SS, Tan ACC, Mathew J, Choi BK. Integrated approach for diagnostics and prognostics of HP LNG pump based on health state probability estimation. Journal of Mechanical Sciences and Technology 2012; 26(11): 3571-3585. http://dx.doi.org/10.1007/s12206-012-0850-4

8. Kiss A, Nowicki R. Monitorowanie i diagnostyka stanu technicznego pomp krytycznych napędzanych 
silnikami elektrycznymi. Napędy i Sterowanie 2015; 5/2015: 72-83.

9. Koo IS, Kim WW. The development of reactor coolant pump vibration monitoring and a diagnostic system in the nuclear power plant. ISA Transactions 2000; 39: 309-316.

http://dx.doi.org/10.1016/S0019-0578(00)00019-7

10. Milovančević M, Tijan E, Karanikić P. Optimization of vibro-diagnostic method for marine rotating pumps. Tehnički Vjesnik 2017; 24(3): 703-707. http://dx.doi.org/10.17559/TV-20160208113305

11. Nazarova MN, Palaev AG. Diagnostics and repair of centrifugal oil transfer pump rotor shaft. IOP Conf. Series: Earth and Environmental Science 2017; 87: 092016.

http://dx.doi.org/0.1088/1755-1315/87/9/092016

12. Shishlyannikov DI, Vasilyeva MA. Operational control and diagnostics of the equipment by the parameters of the electric drive power supply by the example of deep well pump units. IOP Conf. Series: Materials Science and Engineering 2017; 177: 012013.

http://dx.doi.org/10.1088/1757-899X/177/1/012013

13. Siano D, Frosina E, Senatore A. Diagnostic process by using vibrational sensors for monitoring cavitation phenomena in a getoror pump used for automotive applications. Energy Procedia 2017; 126(09): 11151122. http://dx.doi.org/10.1016/j.egypro.2017.08.269

14. Trymucha J. Badanie niezawodności w zakresie analizy i oceny uszkodzeń elementów przepływowego systemu chłodzenia na przykładzie elektrowni Połaniec. Przegląd Elektrotechniczny 2007; 3: 30-34

15. Zhou X, Zhang Y, Ji Z, Chen L. The impeller improvement of the centrifugal pump based on BVF diagnostic method. Advances in Mechanical Engineering 2014: 1-9.

http://dx.doi.org/10.1155/2014/464363

Received 2018-05-06

Accepted 2018-08-03

Available online 2018-08-06

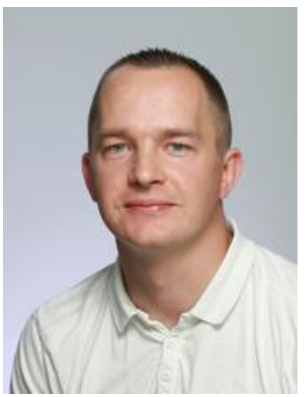

Grzegorz $\dot{Z} Y W I C A, \quad \mathrm{PhD}$, Eng. Since 2005 has been working at the Institute of Fluid Flow Machinery PAN in Gdańsk. Since 2014 he is the Head of the Department of Turbine Dynamics and Diagnostics. His scientific work focuses on: numerical analysis and experimental investigation of rotating machinery, rotor dynamics, bearing systems, designing of microturbines, modal analysis and technical diagnostics.

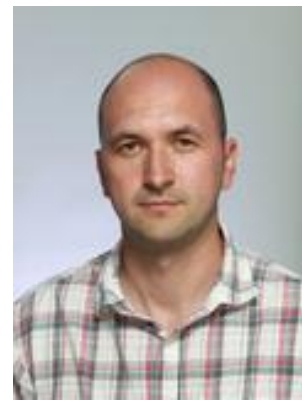

Pawel FLASZYŃSKI, DSc, Eng., Assoc. Prof., received his $\mathrm{PhD}$ degree in mechanical engineering in 2002 and habilitation in 2014 from Gdańsk University of Technology. Since 2014 Head of Aerodynamics Department at the Institute of Fluid Flow Machinery PAN in Gdańsk. Research topics: rotating machinery flows, heat transfer and aerodynamics, flow control, numerical methods.



Tomasz Z. KACZMARCZYK, $\mathrm{PhD}$, Eng. received his M.Sc. Eng. degree in mechanical engineering in 2005 and M.Sc. Eng. degree in electrical and control engineering in 2008 from Gdańsk University of Technology, as well as his $\mathrm{PhD}$ degree in 2012. Since 2013 he has been a research associate at the IMP PAN. From 2014, he works at the Department of Turbine Dynamics and Diagnostics. His main research fields include: heat transfer and heat exchangers, nanofluids, design and construction of steel structures, RES and ORC systems.

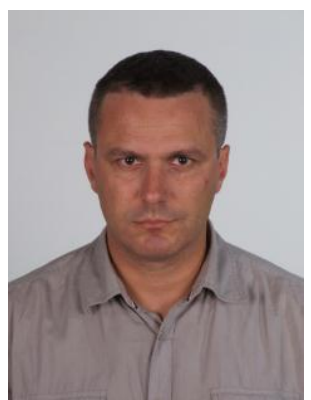

Hubert KOPEĆ, M.Sc. Eng. Since 2008 he worked at the Institute of Aviation in Warsaw. From 2011, he works at the R\&D Department at Group Powen-Wafapomp SA. His main duties include: design of cast and welded structures, review and approve new pump structure and hydraulic designs, identification of structure resonances in accordance of a numerical models, modal analysis, rotor dynamics. 